\title{
Interactions between flagellar and type III secretion proteins in Chlamydia pneumoniae
}

\author{
Chris B Stone, David C Bulir, Jodi D Gilchrist, Raman K Toor, James B Mahony*
}

\begin{abstract}
Background: Flagellar secretion systems are utilized by a wide variety of bacteria to construct the flagellum, a conserved apparatus that allows for migration towards non-hostile, nutrient rich environments. Chlamydia pneumoniae is an obligate, intracellular pathogen whose genome contains at least three orthologs of flagellar proteins, namely Flil, FlhA and FliF, but the role of these proteins remains unknown.

Results: Full length Flil, and fragments of FlhA, FliF, and Flil, were cloned and expressed as either GST or His tagged proteins in E. coli. The GST-tagged full length Flil protein was shown to possess ATPase activity, hydrolyzing ATP at a rate of $0.15 \pm .02 \mu \mathrm{mol} \mathrm{min}{ }^{-1} \mathrm{mg}^{-1}$ in a time- and dose-dependant manner. Using bacterial-2-hybrid and GST pull-down assays, the N-terminal domain of Flil was shown to interact with the cytoplasmic domain of FlhA, but not with FliF, and the cytoplasmic domain of FlhA was shown to interact with the C-terminus of FliF. The absence of other flagellar orthologs led us to explore cross-reaction of flagellar proteins with type III secretion proteins, and we found that Flil interacted with CdsL and CopN, while FlhA interacted with CdsL and Cpn0322 (YscU ortholog CdsU).

Conclusions: The specific interaction of the four orthologous flagellar proteins in C. pneumoniae suggests that they interact in vivo and, taken together with their conservation across members of the chlamydiae sps., and their interaction with T3S components, suggests a role in bacterial replication and/or intracellular survival.
\end{abstract}

\section{Background}

Chlamydia pneumoniae is a gram negative, obligate intracellular pathogen that has been associated with community-acquired pneumonia [1], atherosclerosis [2], arthritis [3], and Alzheimer's disease [4]. C. pneumoniae is characterized by a unique, biphasic life cycle beginning with an infectious, metabolically attenuated elementary body (EB). Chlamydial invasion is initiated by attachment of the EB to the host eukaryotic cell membrane and recruitment of actin to the site of attachment. This remodeling of the actin cytoskeleton is thought to be mediated by the type III secretion (T3S) effector protein, the translocated actin recruitment protein (TARP), which facilitates chlamydial entry into the host cell $[5,6]$. Bacterial uptake involves modulation of the host MEKERK pathway and PI 3-kinase, possibly through the

\footnotetext{
* Correspondence: mahonyj@mcmaster.ca

M.G. DeGroote Institute for Infectious Disease Research, Faculty of Health Sciences and the Department of Pathology and Molecular Medicine, McMaster University, and the Father Sean O'Sullivan Research Centre, St. Joseph's Healthcare, Hamilton, Ontario, Canada
}

action of T3S effectors $[7,8]$. Once internalized, the remainder of the chlamydial life cycle takes place within a parasitophorous membrane-bound vesicle known as an inclusion, where EBs differentiate into the non-infectious, metabolically active form, termed a reticulate body (RB). Within the inclusion, RBs acquire amino acids, nucleotides, lipids and cholesterol from the host cell, events possibly orchestrated via T3S across the inclusion membrane, while at the same time inhibiting apoptosis to ensure survival [9-11]. Golgi fragmentation appears to be a crucial step in intercepting host pathways to obtain these nutrients and compounds, as well as in the maturation of the chlamydiae sps. within the inclusion [12]. The RB interacts with the inclusion membrane until such time as inclusion membrane $R B$ docking sites are no longer available and an unknown signal triggers detachment of the RB from the inclusion membrane followed by asynchronous differentiation into EBs $[13,14]$. The newly formed EBs then exit the cell by either cellular lysis or a packaged release mechanism termed extrusion [15]. 
C. pneumoniae encodes a full set of T3S genes scattered throughout the genome in several fragmented operons. The T3S injectisome has a high amount of paralogy to the flagellar secretion system in structure and in function. In the T3SS, CdsN is the ATPase that aids in shuttling effectors through the needle, and is paralogous to FliI [16]. CdsL is orthologous to YscL and paralogous to FliH. In Yersinia, YscL is the ATPase tethering protein and functions to down-regulate enzymatic activity of $\mathrm{YscN}$ [17]. CopN, orthologous to YopN, is believed to function as a regulator of the system which plugs the injectisome pore prior to activation of T3S and is a known effector protein [18]. CdsU, orthologous to YscU, plays an important role is substrate specificity and substrate switching from structural components to effector proteins upon host cell contact [19]. Recently, several reports have emerged characterizing protein interactions within the C. pneumoniae T3SS, describing novel protein complexes that form at the inner membrane. Johnson et al have shown that CdsD, a unique protein orthologous to $\mathrm{YscD}$ that contains two fork-head associated domains, interacts with the predicted C. pneumoniae ATPase tethering protein, CdsL, and $\mathrm{CdsQ}$, a cytosolic component of the inner membrane that presumably forms the bulk of the T3S C-ring [20]. Stone et al extended these findings to show that $\mathrm{CdsN}$, the ATPase, is also involved in this complex as well as interacting with the proposed plug protein, CopN [16].

Flagellar motility is an ancient, conserved mechanism that may have evolved from the same ancestor as T3S [21]. This motility facilitates bacterial migration towards less hostile environments. In non-motile bacteria, however, the presence of flagella would be evolutionarily redundant and energetically expensive, unless the proteins played a role in another mechanism involving bacterial replication or survival. Although C. pneumoniae is thought to be a non-motile bacteria, it has been shown to contain at least three orthologs of flagellar genes, namely flhA, fliF, and fliI [22,23]. Microarray and proteomic experiments have suggested that these genes are expressed at mid-cycle [23]. The proteins encoded by these genes are paralogs of the T3S proteins $\mathrm{CdsV}$, CdsJ and $\mathrm{CdsN}$, respectively. In motile bacteria, FlhA orthologs are integral membrane proteins required for flagellin export and swarming differentiation which interact with soluble components of the flagellar system [24,25]. FliF orthologs are integral membrane components that form the membrane and supramembrane (MS) ring [26]. FliF forms a base for the other membrane components to form a molecular pore, through which components of the flagella that exist outside the cell membrane are exported. The flagellar ATPase, FliI orthologs, provide energy for construction of the flagellum by aiding in export of flagellar proteins outside the bacterial cell where the proteins form molecular complexes $[27,28]$. The presence of FliI, FlhA and FliF in C. pneumoniae is not sufficient to form a fully functional flagellar apparatus but they could potentially form a rudimentary base for a flagellum structure [29]. In chlamydiae, the identity of other proteins (if they exist) that play important roles in the flagellar apparatus is currently pending, but it is possible that the flagellar apparatus, if it exists, is a hybrid structure of C. pneumoniae T3S and flagellar proteins. Another possibility is that flagellar proteins are involved in T3S, aiding in secretion of effector proteins or structural components. In Pseudomonas, there is evidence to support that flagellar assembly actually antagonizes the T3SS, suggesting a negative cross-regulation of the two systems [30]. No interaction between chlamydial T3S and flagellar components, however, has been reported to our knowledge.

The protein interactions that occur within the bacterial flagellar system have been characterized previously $[29,31,32]$. Genetic evidence, followed by direct biochemical assays, suggests an interaction of FlhA and FliF $[33,34]$. The C-terminal end of FlhA, which is predicted to be cytoplasmic, is known to interact with the soluble components of the flagellar system such as FliI, FliH and FliJ $[34,35]$. FliH acts as a negative regulator of the flagellar ATPase, FliI, and binds FliI as a homodimer, forming a trimeric (FliI)(FliH $)_{2}$ complex [36-38]. FliJ, a second soluble component which interacts with FlhA, acts as a general chaperone for the flagellar system to prevent premature aggregation of export substrates in the cytoplasm, and also interacts with the FliH/FliI complex [39]. This complex of FliI/FliH/FliJ is believed to be crucial for selection of export substrates and construction of the flagellar apparatus, although the proton motive force could play a role in the actual secretion of flagellar proteins $[28,40]$. In C. pneumoniae, FliH and FliJ have not been annotated in the genome.

FliI, the putative C. pneumoniae flagellar ATPase ortholog, has significant amino acid similarity with both CdsN, the C. pneumoniae T3S ATPase, and FliI, the Salmonella flagellar ATPase, suggesting that it possesses enzymatic activity. Here we report an initial characterization of FliI, the flagellar ATPase, and show that it hydrolyzes ATP at a rate similar to that of its T3S ATPase paralog CdsN as well as orthologs in other bacteria $[16,41,42]$. We have also characterized the proteininteractions occurring between FliI, FliF and FlhA, demonstrating a direct interaction of FliI and FlhA, and FlhA and FliF. As well as interactions between the flagellar proteins, we have also characterized four novel interactions between the flagellar and T3S components. The role of these interactions in the chlamydial replication cycle is discussed. 


\section{Results}

\section{Sequence analysis of Flil, FlhA and FliF}

FliI (Cpn0858) is 434 amino acids in length with a predicted molecular mass of $47.5 \mathrm{kDa}$ and a pI of 8.00 . FliI has significant sequence similarity with the $\beta$ subunit of the $\mathrm{F}_{0} \mathrm{~F}_{1}$-ATPase and both its type III secretion paralog, $\mathrm{CdsN}$, and other flagellar ATPases, although the sequence similarity is most striking in the ATPase domain [43]. FliI has a non-conserved N-terminal region (amino acids 1-150) which may be important for mediating protein-protein interactions, a catalytic domain (amino acids 150-329), containing a conserved P loop, Walker A and B domains, and a C-terminal non-conserved domain (amino acids 329-434) of unknown function. Flil has a 34 percent sequence similarity to CdsN, the C. pneumoniae T3S ATPase, and 36 percent similarity with FliI from Salmonella. The active domain of FliI has the most similarity to its paralogs and orthologs, while the $\mathrm{N}$ - and $\mathrm{C}$-terminal regions have the lowest amount of similarity (Figure 1).
FlhA (Cpn0363) is 583 amino acids in length with a predicted molecular mass of $65.6 \mathrm{kDa}$ and a pI of 5.60 . The FlhA paralog in C. pneumoniae is the T3S protein $\mathrm{CdsV}$. FlhA has seven predicted transmembrane regions in the $\mathrm{N}$-terminal half of the protein $\left(\mathrm{FlhA}_{1-308}\right)$, while the $\mathrm{C}$-terminal half of the protein is predicted to be cytoplasmic (TMpred). FlhA from C. pneumoniae has 21 percent sequence orthology with FlhA from Salmonella.

FliF (Cpn0860) is 342 amino acids in length with a predicted molecular mass of $38.2 \mathrm{kDa}$ and a $\mathrm{pI}$ of 9.5 . The FliF paralog in C. pneumoniae is the T3S protein CdsJ. FliF has two predicted TM regions, one located near the $\mathrm{N}$-terminus and one located near the C-terminus. FliF from C. pneumoniae is only 15 percent similar to FliF from Salmonella.

\section{Expression and ATPase activity of Flil}

FliI has significant similarity with many characterized ATPases, and this led us to explore the ATPase activity

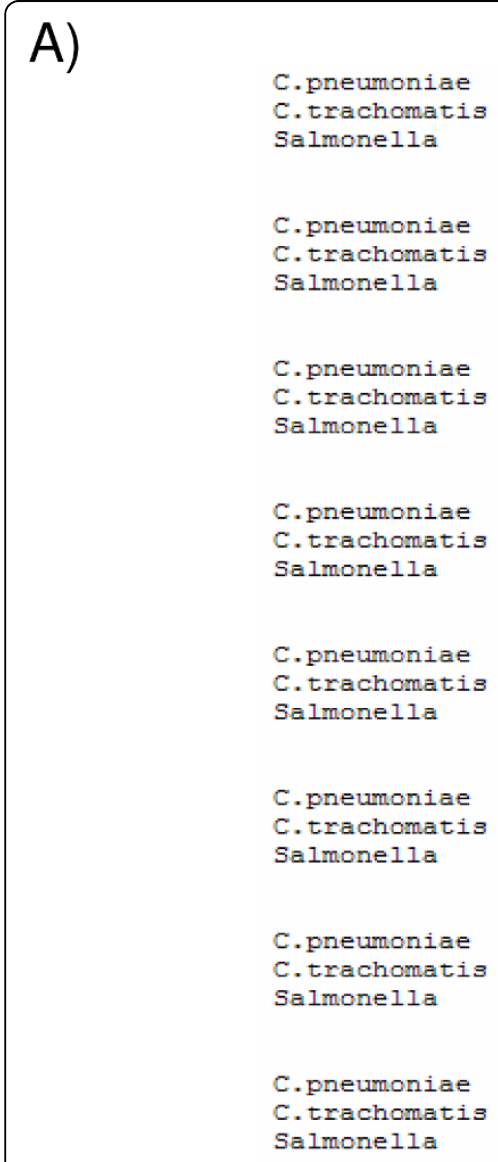

VFHHVSEFTERAGN--NDKGSITALYATLYYPK-HPDIFTDYLKSILDGHFFITS-QGKA 338 VFHHVAE FLERAGN--NDKGSITSFYAILHYAN-HPDIFTDYVKSLLDGHFFLSP-QEKS 338 VFAKL PALVERAGNGIHGGGSITAFYTVLTEGDDQQDPIADSARAILDGHIVLSRRLAEA 360

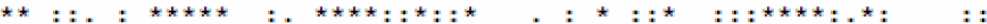

LASPPIDILSSLSRSAQALALPHHYAAAERLRSLLKVYNEALDI IHLGAYT PGQDEELDK 398 FSSPPINVLISLSRSSRQLALPHHYAAAQELLSLLKAYHEAIDIIQLGAYVSGQDAHLDR 398 GHYPAIDIEASISRAMTALITEQHYARVRLFKQLLSSFQRNRDLVSVGAYAKGSDPMLDK 420

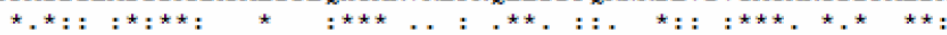

AVKLLPSIKAFLAQPLSSYCYLDNTLKQLEALADS- 433 AIRLLPSVKQFLSQPYSHYSAIHETIEQLCQLLKHE 434 AITLWPQLEAFLQQGIFERADWEDSLQALDLIFPTV 456 $\star: \star \star .:: \star \star \star *$. . : : : * :

Figure 1 Sequence conservation of Flil from C. pneumoniae with C. trachomatis and Salmonella. Sequence alignment (ClustalW) of the full length Flil protein from C. pneumoniae, C. trachomatis, and Salmonella. Asterisk refers to identical amino acids, a double dot refers to a conserved substitution and a single dot refers to a semi-conserved substitution. Outlined is the conserved P loop region in the Walker A domain. 
of this protein. Purified GST tagged FliI was tested for its ability to hydrolyze ATP using the malachite green binding assay. Figure 2A shows that GST-FliI was essentially free of contaminating proteins by SDS-PAGE and anti-GST Western blot (left) or Coomassie blue stain (right). GST-FliI hydrolyzed ATP in a dose- and timedependant manner at a rate of $0.15 \pm .02 \mu \mathrm{mol} \mathrm{min}{ }^{-1}$ $\mathrm{mg}^{-1}$ (Figure 2B i and ii, diamonds). This level of activity is comparable to other flagellar ATPases as well as the T3S paralog, CdsN $[16,41,42]$. ATPase activity of GSTFliI peaked at $37^{\circ} \mathrm{C}$, and at a pH of 8.0 (Figure 2 iii and iv). Another GST-tagged protein, GST-CopN, purified in the same manner as GST-FliI had negligible ATPase activity (Figure 2B i and ii, squares).

\section{FlhA interacts with FliF}

FlhA is known to interact with the MS ring protein, FliF, in other flagellar systems [33,34]. We explored the interactions of these two proteins in C. pneumoniae. Two fragments of FliF were cloned and expressed as His-tagged proteins. His-FliF ${ }_{1-271}$ lacked the distal Cterminal 70 amino acids while His- $\mathrm{FliF}_{35-341}$ lacked the $\mathrm{N}$-terminal 35 amino acids. Each fragment contained only one of the two predicted TM regions. FliF ${ }_{1-271}$ migrated with an apparent molecular weight of $30 \mathrm{kDa}$, while His-FliF ${ }_{35-341}$ migrated at $34 \mathrm{kDa}$. FlhA was cloned and expressed as a soluble fragment with either a GST or His tag. FlhA $\mathrm{A}_{308-583}$ encoded the C-terminal half of the protein, lacking the stretch of seven TM domains. Expression and detection of His-FlhA $\mathrm{A}_{308-583}$

A)
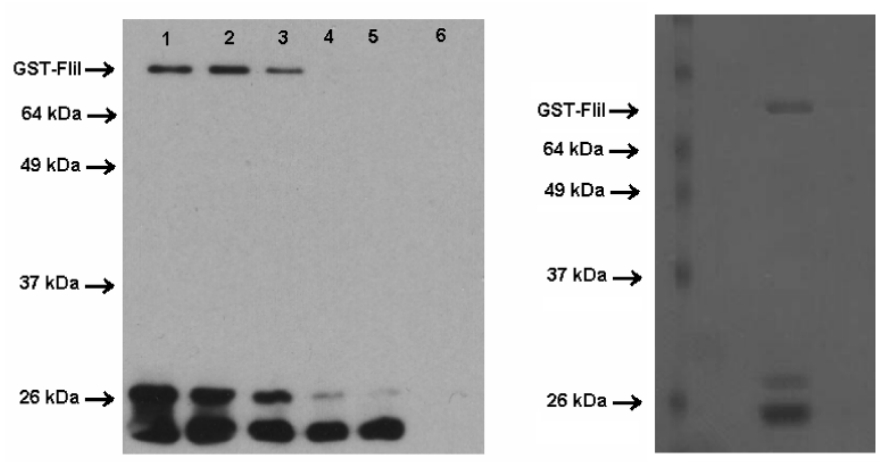

B)

i)

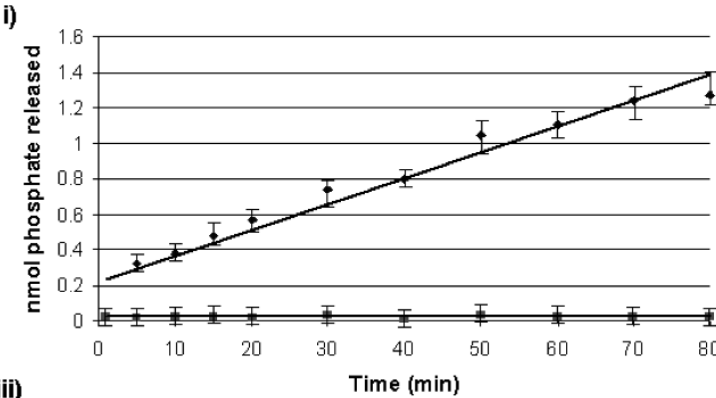

iii)

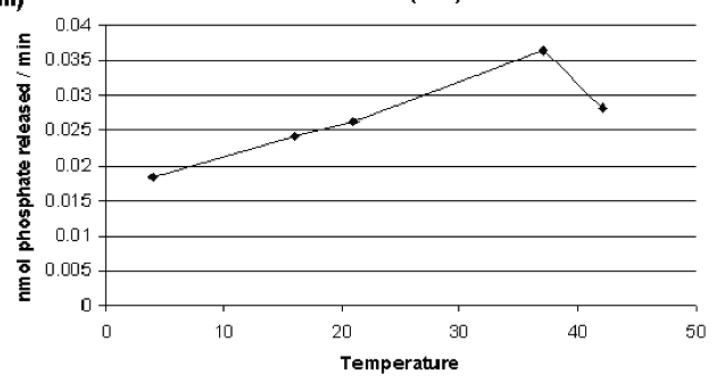

ii)

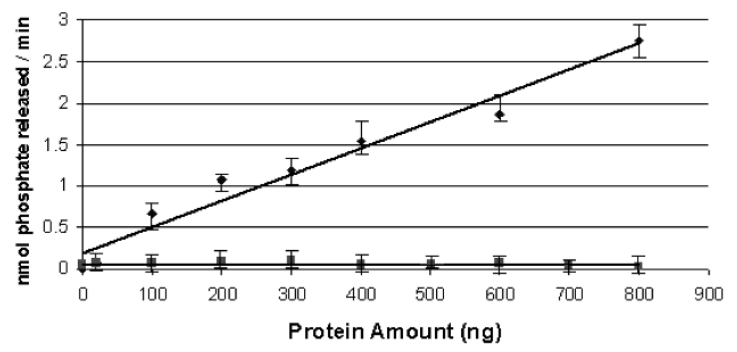

iv)

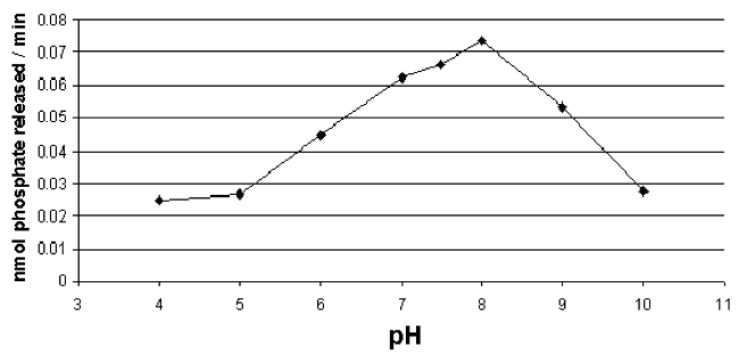

Figure 2 Expression, purification, and optimal conditions for the time- and dose-dependant ATPase Flil. A: GST-Flil eluted off a glutathione column (1 mL aliquots) and electrophoresed on an 11\% SDS-PAGE gel and either probed for by anti-GST Western blot (left) or stained by Coomassie blue (right). GST-Flil migrated at approximately $73 \mathrm{kDa}$, its predicated molecular mass. Numbers refer to the eluted fraction. B: i) Time course of purified GST-Flil ATP hydrolysis (diamonds) and GST-CopN ATP hydrolysis as a negative control (squares). ii) Inorganic phosphate released at different concentrations of GST-Flil (diamonds) and GST-CopN as a negative control (squares) iii) GST-Flil ATPase activity at either $4^{\circ} \mathrm{C}, 16^{\circ} \mathrm{C}, 23^{\circ} \mathrm{C}, 37^{\circ} \mathrm{C}$ or $42^{\circ} \mathrm{C}$. iv) GST-Flil ATPase activity at varying $\mathrm{pH}$. 
used as the bait protein in GST pull-down assays migrated at the expected molecular weight of $30 \mathrm{kDa}$. We used the bacterial-2-hybrid assay to test for interactions between FliF and FlhA. Full length FlhA interacted significantly with full length FliF, with a $\beta$-galactosidase activity of $847.2 \pm 21.2$ units of activity, as compared with a negative control value of $412.0 \pm 82.4$ units of activity (Table 1). We next used GST pull-downs to confirm the interactions found by the bacterial-2-hybrid system and to determine the exact regions of the proteins mediating these interactions (Figure 3A). All protein complexes were washed with either low or high salt buffers containing $0.1 \%$ Triton X-100 to dissociate spurious protein-protein interactions. GST-Flh $\mathrm{A}_{308-583} \mathrm{co}-$ purified with His-FliF $35-341$ but not His-FliF 1-271 , suggesting that the C-terminus of FliF (amino acids 271341 ) is required for interactions with the cytoplasmic portion of FlhA.

\section{Flil interacts with FlhA}

In orthologous systems, it has been shown that FlhA interacts with several soluble

components of the flagellar machinery, including the ATPase, FliI [34]. Therefore, we investigated the possibility of whether FlhA interacts with FliI in C. pneumoniae. The bacterial-2-hybrid system was initially used to screen for potential protein interactions. FlhA interacted with FliI, with $\beta$-galactosidase activity of $942.9 \pm 123.1$ units of activity as compared to the negative control with a value of $412.0 \pm 82.4$ units of activity (Table 1 ). To confirm these protein-protein interactions we used
GST pull-down assays (Figure 3B). Initially FliI was cloned as three constructs, full length FliI, a C-terminal truncation of FliI (FliI ${ }_{1-400}$ ) and a N-terminal truncation of FliI (FliI $150-471)$. These three constructs were tested for interaction with the His-FlhA $\mathrm{A}_{308-583}$ construct. Full length GST-FliI co-purified with His-Flh $\mathrm{A}_{308-583}$, suggesting that the cytoplasmic fragment of FlhA contains the interactive domain. To determine the region of FliI that interacts with FlhA, we reacted the two truncation constructs of FliI with the cytoplasmic domain of FlhA. Only FliI ${ }_{1-400}$ was able to co-purify with FlhA, and not FliI $_{150-471}$, suggesting that the FlhA binding domain resides in the N-terminal 150 amino acids of Flil (Figure 3B). We next wanted to know if FliI interacts with FliF. We therefore reacted GST-FliI against the two FliF constructs and found that there was no co-purification, suggesting that any interaction between FliI and FliF, if there is an association, would seem to be indirect and mediated through the action of FlhA or other intermediate proteins (Figure 3C).

\section{Cpn0859 interacts with Flil and FlhA}

Cpn0859 is a predicted 179 amino acid protein with a PI of 6.10 and a molecular mass of $20.3 \mathrm{kDa}$. The Cpn0859 ORF is encoded directly upstream of $f l i F$ and downstream of fliI, the flagellar ATPase. Based on its location relative to FliI and FliF, we hypothesized that it may interact with other flagellar components. We used GST pull-down assays to explore this possibility. Initial GST pull-downs indicated that full length His-Cpn0859 interacts with GST-Cpn0859, suggesting the presence of a

Table 1 Interaction between the flagellar proteins of $C$. pneumoniae using the Bacterial-2-hybrid System

\begin{tabular}{lll}
\hline Plasmids & $\beta$-Galactosidase Activity in units/mg bacteria & \\
\hline Negative Control & & Protein Functions \\
pT18 + pT25 & $412.0 \pm 82.4$ & pT18: Empty vector \\
Positive Control: & & pT25: Empty vector \\
pT18-PknD + pT25-CdsD-FHA-2 & $996.3 \pm 50.0$ & Flil: Putative flagellar ATPase \\
Negative Interactions: & & FliF: Putative flagellar MS ring protein \\
PT18-Flil + pT25-FliF & $396.4 \pm 32.1$ & FlhA: Putative flagellar integral membrane \\
PT18-FliF + pT25-Cpn0859 & $421.1 \pm 25.9$ & protein \\
pT18-Flil + pT25-Cpn0706 & $404.4 \pm 19.5$ & Cpn0859: Hypothetical C. pneumoniae \\
pT18-Cpn0706 + pT25-FlhA & $443.0 \pm 32.3$ & protein \\
Positive Interactions: & & Cpn0706: Putative T3S chaperone \\
pT18-FliF + pT25-FlhA & $847.2 \pm 21.2$ & CdsL: Putative T3S ATPase tethering \\
PT18-Flil + pT25-FlhA & $942.9 \pm 123.1$ & protein \\
PT18-Flil + pT25-CdsL & $874.3 \pm 59.3$ & CopN: Putative T3S plug protein \\
pT18-Flil + pT25-CopN & $943.2 \pm 74.2$ & Cpn0322: Putative CdsU ortholog \\
pT18-Cpn0322 + pT25-FlhA & $779.9 \pm 32.7$ & \\
pT18-CdsL + pT25-FlhA & $832.1 \pm 23.3$ & \\
\hline
\end{tabular}

* Flil, Flif, FlhA, CdsL, CopN, Cpn0706 and Cpn0322 were cloned into both the pT18 and pT25 vectors. The bacterial-2-hybrid was performed in triplicate as described in the Materials and Methods section. Empty pT18 and pT25 vectors were used as a negative control while pT18-PknD + pT25-CdsD-FHA-2 was used as a positive control. The cut off for a positive interaction ( 577 units of activity/mg protein), is the mean of the negative control values (empty pT18 + pT25) plus two standard deviations obtained from 20 assays. 


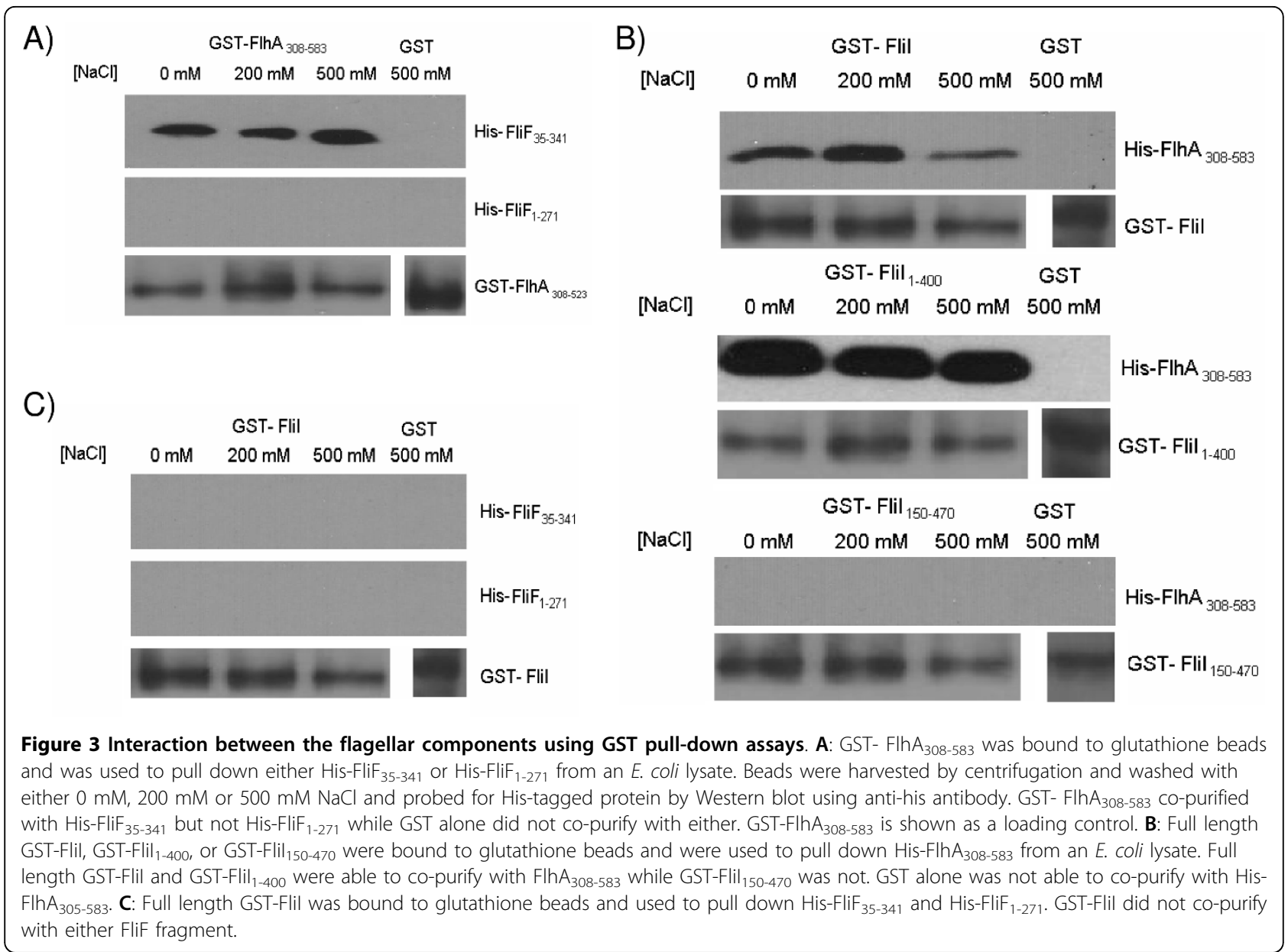

dimerization domain (Figure 4A). To explore this observation we treated $\mathrm{Cpn} 0859$ with formaldehyde prior to PAGE and observed the presence of a monomer and a dimer, migrating with apparent molecular weights of 22 $\mathrm{kDa}$ and $45 \mathrm{kDa}$ (Figure 4B). We next explored the possible interaction of Cpn0859 with other flagellar proteins in C. pneumoniae. Using GST pull-downs, His-Cpn0859 co-purified with the full length GST-FliI protein as well as the GST-FliI ${ }_{1-400}$ protein, but not GST-FliI ${ }_{150-471}$ (Figure 4C). This suggests that Cpn0859 binds to the Nterminus of FliI. GST pull-down assays showed an interaction between Cpn0859 and the $\mathrm{FlhA}_{308-583}$ protein, the cytoplasmic domain of FlhA (Figure 4D). Cpn0859 did not co-purify with either $\mathrm{FliF}_{35-341}$ or $\mathrm{FliF}_{1-271}$ (Figure 4D), suggesting that $\mathrm{Cpn} 0859$ does not interact with FliF.

\section{Flil and FlhA interact with T3S components}

Since Chlamydia have no apparent flagella, we investigated whether the flagellar proteins FliI, FlhA and FliF interact with T3S components. Using bacterial-2-hybrid screening we found that FliI and FlhA interacted with CdsL, the putative T3S ATPase regulator and tethering protein, with a $\beta$-galactosidase activity of $874.3 \pm 59.3$ and $832 \pm 23.3$ units of activity, respectively. FliI also interacted with CopN, the putative T3S plug protein, with a $\beta$-galactosidase activity of $943.2 \pm 74.2$ units of activity. We also found that FlhA interacted with the putative $\mathrm{YscU}$ ortholog, $\mathrm{CdsU}$, with a $\beta$-galactosidase activity of $779.9 \pm 32.7$ units of activity, as well as CdsL, with a $\beta$-galactosidase activity of $832.1 \pm 23.3$ units of activity (Table 1). To corroborate these findings we utilized GST pull-down assays and showed that GST-FliI interacted with CdsL and CopN, but not Cpn0706 (Figure 5A), and GST-FlhA co-purified with both CdsL and CdsU (Figure 5B). Control GST coated beads did not co-purify with CdsL, CopN or CdsU.

\section{Discussion}

Sequencing of several Chlamydial genomes revealed a conserved set of flagellar orthologs, despite the fact that C. pneumoniae lack a flagellum and are considered non- 


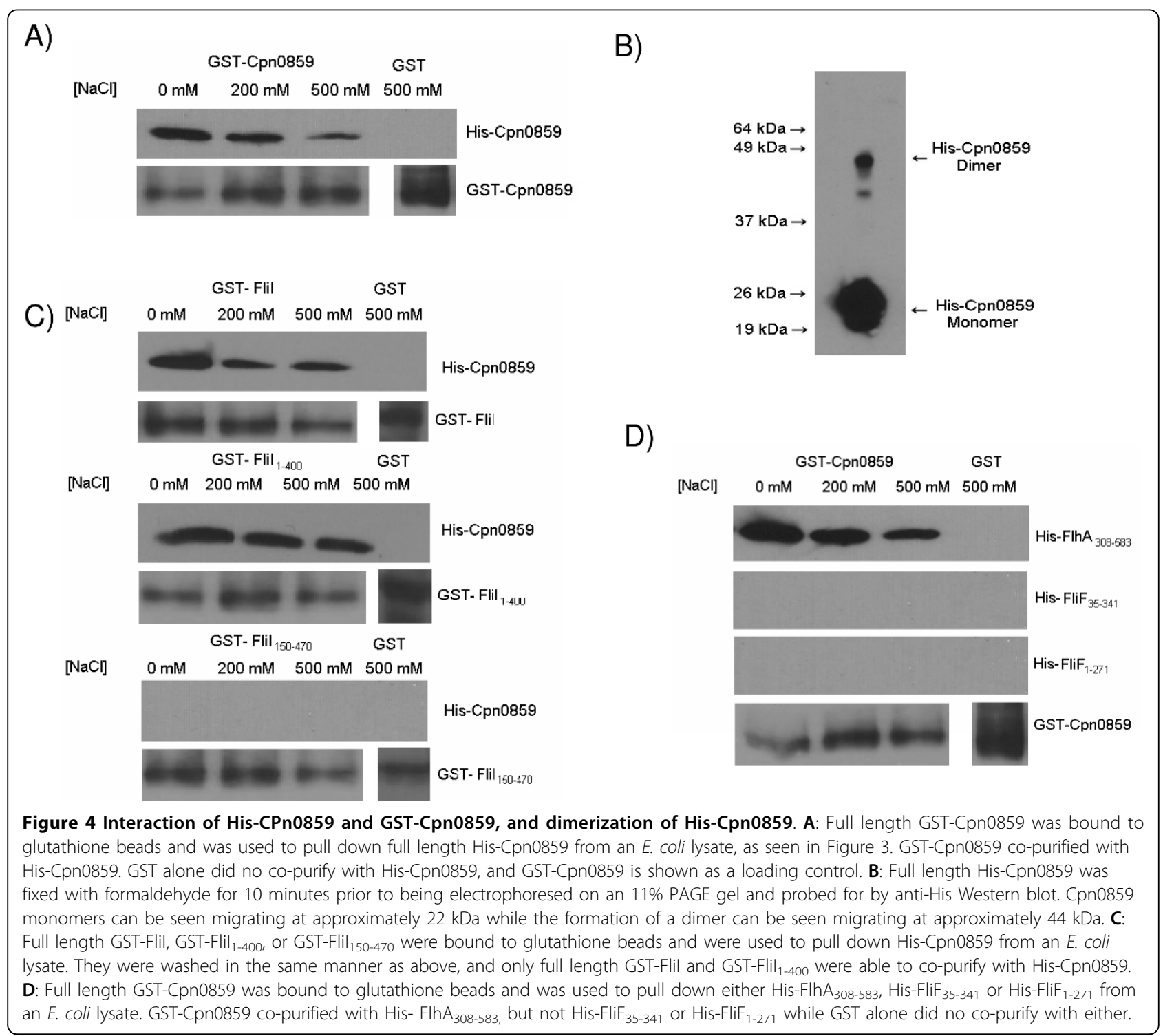

motile bacteria [22,23]. Here we report an initial characterization of three annotated flagellar proteins of $C$. pneumoniae, FliI, FlhA and FliF, demonstrating ATPase activity of FliI and interactions between these flagellar orthologs. We have demonstrated that FliI hydrolyzes ATP in a linear, time-and dose-dependant manner, with optimal activity at a $\mathrm{pH}$ of 8.0 and a temperature of $37^{\circ}$ C. FliI also interacts with the cytoplasmic domain of FlhA, while FlhA interacts with the C-terminal region of the FliF protein. No direct interaction of FliI and FliF was detected. Also, we have characterized an interaction of both FlhA and FliI with Cpn0859, a fourth unannotated protein. We also show that FliI interacts with CdsL and CopN, two T3S components, while FlhA interacts with CdsL and a third T3S component, CdsU. Collectively, this data suggests that the flagellar proteins of $C$. pneumoniae interact in a specific way with T3S proteins and may play an important, as yet unidentified role in the chlamydial replication cycle.

FliI hydrolyzes ATP in a linear, time- and dose-depen-

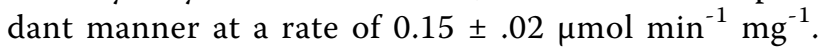
This rate is typical of other secretion ATPases such as CdsN, EscN, or FliI from other bacterial species $[16,41,42]$. The optimal $\mathrm{pH}$ for FliI ATPase activity is 8.0, which is the same as that for other flagellar ATPases [42]. Extreme low or high pH greatly reduced the activity, possibly due to protein denaturation. Also, the enzyme activity peaked at a temperature of $37^{\circ} \mathrm{C}$ and declined substantially beyond that. Although the formation of higher-order complexes was not explored here, other flagellar ATPases are thought to form a hexameric complex [44]. 


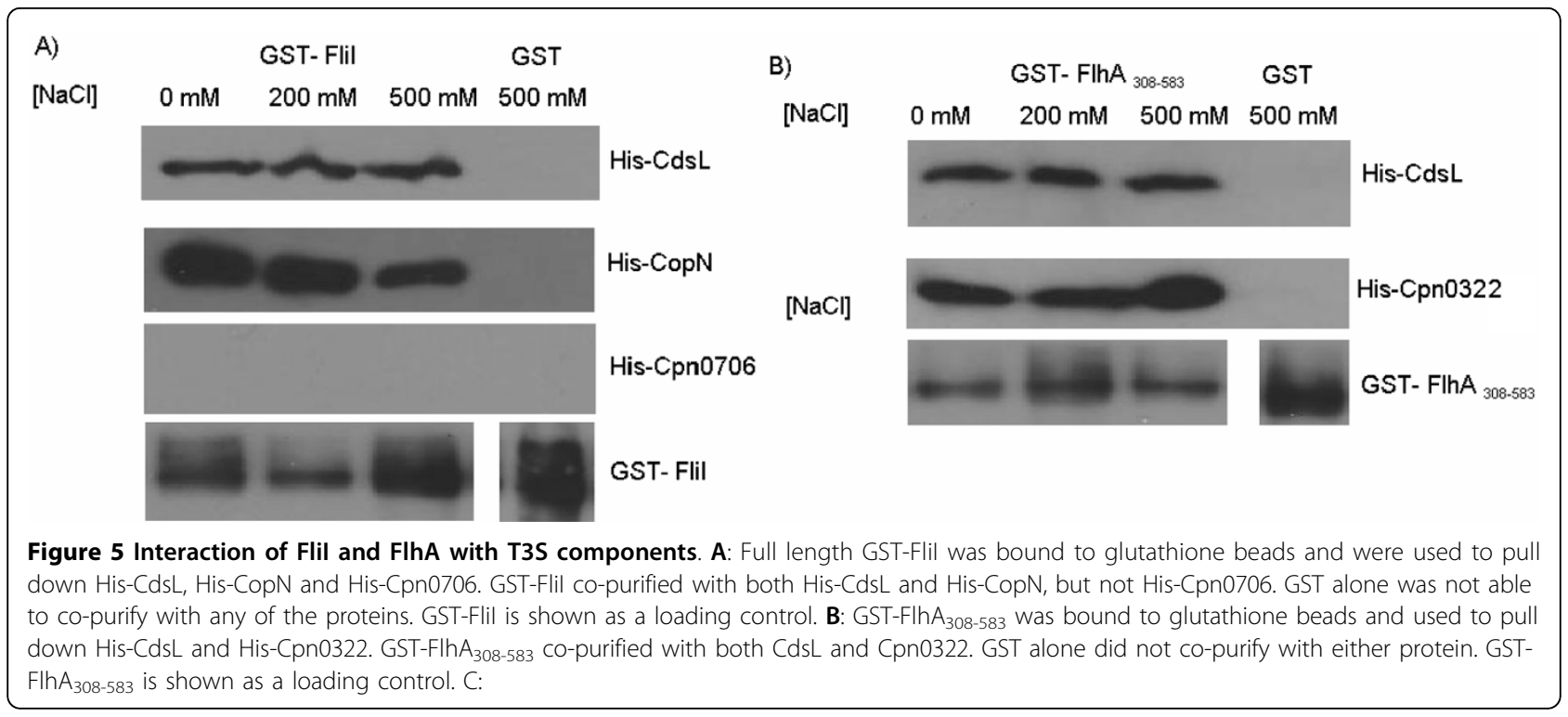

The presence of three flagellar genes in chlamydiae is intriguing since chlamydiae are thought to be nonmotile and not to possess flagella. FliF, FlhA and FliI alone do not contain all the necessary components for a functional flagella or secretion apparatus, however, a rudimentary basal body or pore complex could be formed by these three components. It is known that the most rudimentary flagellar structure that can be assembled is the MS ring, which consists of only the FliF protein [29]. We have shown that these proteins interact with one another (FliI, FlhA and FliF), most likely at the inner membrane of C. pneumoniae. The interaction between Flil and FlhA is mediated by the Nterminal 150 amino acids of FliI and appears to be specific since it is not disrupted by high salt $(500 \mathrm{mM})$. Only the cytoplasmic domain of FlhA (amino acids 308583) was utilized in the GST pull-down, suggesting that any protein interactions that occur are within this region. Protein interaction studies with the full length FlhA protein are difficult due to the presence of seven transmembrane domains rendering full length FlhA insoluble and making this portion of the protein unable to bind to soluble flagellar components. Since FlhA is known to interact with soluble components of the flagellar apparatus in other bacteria, it is expected that the cytoplasmic domain mediates an interaction with FliI [25]. FliF is known to form the MS ring in flagellated bacteria, and is one of the first components of the flagellar basal body to be incorporated into the membrane $[26,29]$. We detected an interaction of the C-terminal 70 amino acids of FliF with the cytoplasmic domain of FlhA. These interactions were also stable in $500 \mathrm{mM}$ $\mathrm{NaCl}$, suggesting that the interaction is specific. We did not, however, detect any interaction between FliI and
FliF, suggesting that any interaction between those two components may be mediated through the action of another protein, possibly FlhA

In C. pneumoniae, Cpn0859 is encoded directly downstream of the ATPase, which led us to explore any interactions Cpn0859 may have with other flagellar proteins. We initially found that Cpn0859 was able to interact with itself using a GST pull-down assay, suggesting that it could form dimers in solution. To confirm this observation we utilized formaldehyde fixation followed by PAGE analysis to visualize the formation of dimers. Using this method we saw that Cpn0859 migrated in two molecular forms, with sizes corresponding to both monomers and dimers. We then explored possible interactions between Cpn0859 and the other flagellar proteins and detected interactions of Cpn0859 with both FliI and FlhA, but not FliF. Cpn0859 bound to the N-terminal 150 amino acids of FliI and the cytoplasmic region of FlhA. The interaction of Cpn0859 with the cytoplasmic domain of FlhA was expected as FlhA is known to interact with soluble components of other flagellar systems [34]. We considered the possibility that Cpn0859 may in fact be the FliH ortholog in C. pneumoniae as Cpn0859 has minor sequence orthology to other FliH proteins, but after further investigation we found that Cpn0859 did not appear to play a regulatory role with FliI (data not shown). Figure 6 summarizes the interactions between FliI, FlhA and FliF (Figure 6A) and interactions between Cpn0859, FlhA and FliI (Figure 6B).

Bacterial type III secretion (T3S) and flagellar secretion systems are structurally similar, and may have a common ancestry [21]. Although C. pneumoniae does not contain a full repertoire of flagellar genes, it does encode a complete T3S system which most likely 


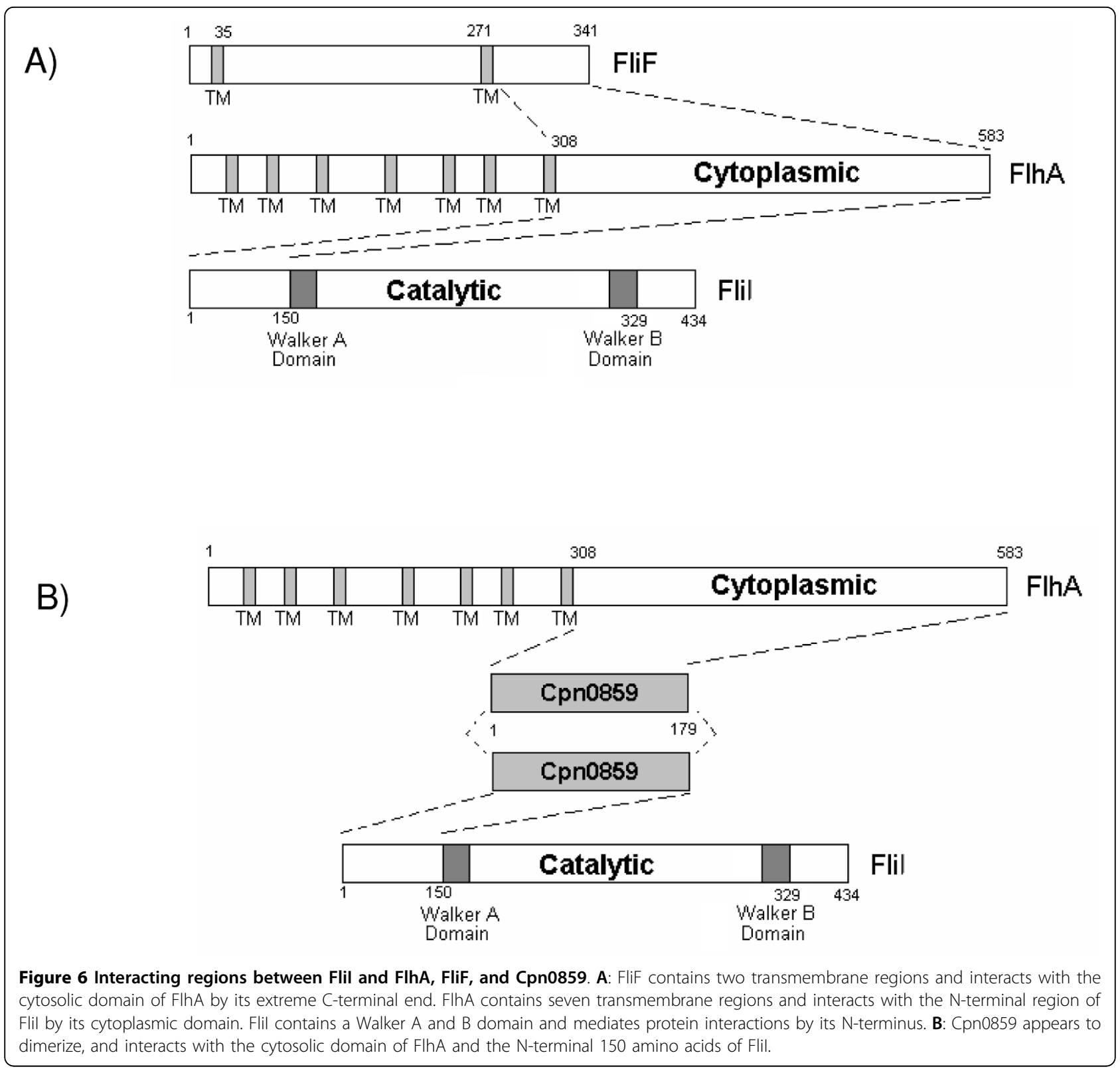

consists of specific protein complexes located in the inner membrane $[16,20,23]$. We have characterized an interaction of FliI with CdsL, the T3S ATPase tethering protein. The C. pneumoniae FliH ortholog has not yet been identified, and in the absence of $\mathrm{FliH}, \mathrm{CdsL}$ may play a regulatory role for both FliI and CdsN. FliI also interacts with the CopN, the T3S plug protein, suggesting that FliI may be involved in either the secretion of effector proteins or regulation of the T3S system. YscU orthologs have a flagellar paralog, FlhB, and Cpn0322 is believed to be the $C$. pneumoniae YscU ortholog (CdsU). FlhB is known to interact with FlhA, but in $C$. pneumoniae no FlhB ortholog has been annotated. We found that FlhA interacts with $\mathrm{CdsU}$, suggesting integration of FlhA into the inner membrane, associating with T3S components.

\section{Conclusions}

Based on all of our observations, it is possible that the flagellar proteins may interact with components of the T3S injectisome, forming a hybrid structure, thereby playing an ancillary or accessory role in secretion of type III effectors across either the cytoplasmic or inclusion membrane. Another possibility is that there are other, as yet unannotated proteins that play a role in a putative flagellar system in C. pneumoniae. For example, along with the FliH/FliI complex that is formed in other bacteria, another protein, FliJ, which is a general 
chaperone, is believed to be involved in this complex $[39,44]$. FliJ has not been identified in C. pneumoniae. In the absence of a genetic manipulation system for the chlamydiae, direct evidence for the role of these flagellar proteins remains elusive. The fact that FliI is enzymatically active and forms complexes in vitro with other flagellar proteins, all of which are present in all other chlamydiae sps. studied to date, suggests that these proteins play an important role in chlamydial replication or survival. Further studies using heterologous systems and genetic complementation could help to decipher the exact role of these flagellar proteins in chlamydiae.

\section{Methods}

\section{Expression Plasmids}

C. pneumoniae CWL029 (VR1310:ATCC) (GenBank accession \# AE001363) was the strain used to isolate genomic DNA for cloning and protein expression. Full length fliI, Cpn0859, cdsL, copN, Cpn0322, and fragments of flhA, fliF, and fliI were amplified from CWL029 using AttB-containing primers (Gateway; Invitrogen). The amplified products were cloned into $\mathrm{pDONR}_{201}$ (Gateway; Invitrogen) to generate pENT vectors. The pENT vectors were then used in LR reactions (Gateway; Invitrogen) to produce $\mathrm{pEX}$ vectors containing the genes of interest. We used either $\mathrm{pEX}_{17}(\mathrm{~N}$ terminal His tag) or $\mathrm{pEX}_{15}$ (N terminal GST tag) vectors for our protein expression. All constructs were confirmed by sequencing at the Molecular Biology Facility at McMaster University.

To identify protein interactions we utilized the bacterial-2-hybrid system [39]. Genes of interest were cloned into either pT18 or pT25 plasmids, each of which expresses a different fragment of adenylate cyclase. When these two plasmids are co-transformed, expressing the protein of interest fused to the adenylate cyclase fragment, any interaction between the two proteins results in production of cAMP. Increases in cAMP results in an increase in the $\beta$-galactosidase gene that can be monitored using $\beta$-galactosidase activity assays. pT18 and pT25 were digested with KpnI (New England Biolabs) as well as genes amplified from CWL029 (fliI, flhA, fliF, cdsL, Cpn0322, copN) that had a KpnI site designed into the primers. Ligation was performed overnight at $16^{\circ} \mathrm{C}$ using $\mathrm{T} 4$ Ligase (Invitrogen) and the resulting mixture was used to transform $E$. coli XL-1 cells and transformants were selected on $100 \mu \mathrm{g} / \mu \mathrm{L}$ ampicillin and $34 \mu \mathrm{g} / \mu \mathrm{L}$ chloramphenicol (Luria Bertani) LB plates. Plasmids were prepared using the GenElute Plasmid Miniprep Kit (Sigma).

\section{Protein Expression}

All constructs were expressed in E. coli Rosetta pLysS. Expression plasmids were used to transform $E$. coli Rosetta
pLysS and plated on LB plates containing $100 \mu \mathrm{g} / \mathrm{mL}$ ampicillin. LB broth $(750 \mathrm{~mL})$, containing antibiotics, was then inoculated with $12 \mathrm{~mL}$ of an overnight culture and grown at $37^{\circ} \mathrm{C}$ until they reached an optical density (OD) 600 of approximately 0.8 . Cultures were then cooled on ice to $20^{\circ} \mathrm{C}$ and induced with $0.2 \mathrm{mM}$ of isopropyl $\beta$-D galactosidase (IPTG). Cultures were then incubated at $23^{\circ} \mathrm{C}$ for 2 hours and bacteria were harvested by centrifugation at $6500 \times \mathrm{g}$ for 10 minutes in a Sorvall RC-5B centrifuge and washed with ice-cold phosphate buffered saline (PBS). Bacteria containing His-tagged protein were resuspended in Binding Buffer (50 mM potassium phosphate $\mathrm{pH} 7.2$, $150 \mathrm{mM} \mathrm{KCl}, 1 \mathrm{mM} \mathrm{MgCl} 2$ ) while the bacteria containing GST-tagged protein were resuspended in PBS and stored at $-20^{\circ} \mathrm{C}$ until further use.

\section{Purification of Recombinant Proteins}

E. coli pellets containing over-expressed proteins were thawed on ice and sonicated using a Fischer Scientific Sonic Dismembrator Model 100, followed by centrifugation at 20,000 $\times$ g for 40 minutes to remove insoluble material. Supernatants containing His-tagged protein were stored at $4{ }^{\circ} \mathrm{C}$ for use in GST pull-down assays while the GST-tagged protein supernatents were filtered through $0.45 \mu \mathrm{m}$ acrodisc filters (Pall Corporation) and incubated overnight at $4^{\circ} \mathrm{C}$ with $300 \mu \mathrm{L}$ of Glutathioneagarose beads (Sigma). For GST pull-down assays, beads were blocked overnight in Tris Buffered Saline with $0.1 \%$ Tween-20 and $4 \%$ BSA and stored at $4{ }^{\circ} \mathrm{C}$ until use. For ATPase activity measurements, glutathione beads were washed on a column with PBS $+0.1 \%$ Tween until the flow-through had an $\mathrm{OD}_{280}$ of less than 0.005. GSTtagged protein was then eluted off the beads using 1.5 $\mu \mathrm{g} / \mu \mathrm{L}$ reduced glutathione (Sigma) and dialyzed against activity buffer (50 mM Tris-HCL pH 7.0, $5 \mathrm{mM} \mathrm{MgCl}_{2}$, $10 \mathrm{mM} \mathrm{KCl}$ ). Purity was confirmed using SDS-PAGE and Coomassie blue staining.

\section{Dimerization Assay}

In order to determine whether Cpn0859 formed dimers, formaldehyde fixation and non-denaturing PAGE were used. His-Cpn0859 was purified from Ni-NTA beads, dialyzed against PBS and concentrated using Amicon 10 $\mathrm{kDa}$ (Millipore) concentrators to a final concentration of $1 \mu \mathrm{g} / \mu \mathrm{l}$. Formaldehyde was added to purified HisCpn0859 to a final concentration of $10 \%$ and fixation was allowed to continue for 10 minutes. Samples containing $1 \mu \mathrm{g}$ of Cpn0859 were electrophoresed on an 8\% non-denaturing PAGE and visualized by Western blot using anti-His antibody (Sigma).

\section{ATPase Activity}

ATP hydrolysis by GST-Flil purified from glutathioneagarose beads was measured using a malachite green 
assay ( $\mathrm{R} \& \mathrm{D}$ Systems). For all experiments, the specific activity was determined using the equation of a standard line generated using phosphate standard ( $R$ \& D Systems). Reaction mixtures contained 150 ng of GST-FliI, $4 \mathrm{mM}$ ATP, $50 \mathrm{mM}$ Tris-HCL pH 7.0, $5 \mathrm{mM} \mathrm{MgCl}_{2}$, and $10 \mathrm{mM} \mathrm{KCl}$. The reaction mixture $(1 \mathrm{~mL})$ was incubated at $37^{\circ} \mathrm{C}$ for 1 hour and $50 \mu \mathrm{L}$ of the mixture was taken for inorganic phosphate determination at various time points. The reaction was stopped by the addition of $10 \mu \mathrm{L}$ of Malachite Green Reagent A followed by 10 $\mu \mathrm{L}$ of Malachite Green Reagent B and incubated at room temperature for one minute before an $\mathrm{OD}_{610}$ reading was taken, according to the manufacturer's instructions. For the negative control, purified FliI was digested for 10 minutes at $37^{\circ} \mathrm{C}$ using Proteinase $\mathrm{K}$ (Invitrogen). Also, as a negative control, another GSTtagged protein (CopN) known not to have ATPase activity was purified in the same manner and tested for activity. ATPase activity was expressed as $\mu \mathrm{mol}$ phosphate released $\mathrm{min}^{-1} \mathrm{mg}^{-1}$ of protein, and all experiments were performed in triplicate.

\section{GST Pull-down Assays}

To examine the interaction of the flagellar proteins, GST pull-down assays were performed as described previously with the following modifications [20]. Briefly, glutathione agarose beads $(30 \mu \mathrm{L})$ bound to fifty nanograms of GST tagged FliI, Cpn0859, or FlhA was used in the assay. The beads were incubated overnight at $4^{\circ} \mathrm{C}$ with the E. coli lysate expressing the His-tagged proteins. The beads were collected by centrifugation and washed with increasing concentrations of $\mathrm{NaCl}$ to eliminate spurious protein interactions. All proteins were eluted from the Glutathione beads and electrophoresed on an 11\% SDS-PAGE gel before being probed for Histagged protein. As a negative control, GST alone was incubated on beads with the $E$. coli lysates.

\section{Bacterial-2-Hybrid Assay}

The bacterial-2-hybrid assay uses protein-protein interactions to bring two fragments of adenylate cyclase catalytic domain together to produce cAMP, stimulating $\beta$ galactosidase activity. $\beta$-galactosidase activity is therefore a representation of protein interaction. This protocol was performed as described by Karimova et al, 2005 [45]. Briefly, E. coli DHP-1 cells (an adenylate cyclase deficient cell line) were transformed using pT18-FliI/ pT18-FlhA/pT18-FliF and either pT25-FlhA or pT25FliF and selected with $100 \mu \mathrm{g} / \mu \mathrm{L}$ ampicillin and $34 \mu \mathrm{g} /$ $\mu \mathrm{L}$ chloramphenicol. Three individual colonies were selected from each plate and grown overnight in $3.0 \mathrm{~mL}$ of $\mathrm{LB}$ at $30^{\circ} \mathrm{C}$ in the presence of $0.5 \mathrm{mM}$ IPTG plus appropriate antibiotics. Overnight culture $(200 \mu \mathrm{L})$ was diluted 1 in 5 into M63 buffer $\left(75 \mathrm{mM}\left(\mathrm{NH}_{4}\right)_{2} \mathrm{SO}_{4}, 110\right.$
$\mathrm{mM} \mathrm{KH}{ }_{2} \mathrm{PO}_{4}, 200 \mathrm{mM} \mathrm{K} \mathrm{HPO}_{4}, 5 \mathrm{mM} \mathrm{FeSO}_{4}-7 \mathrm{H}_{2} \mathrm{O}$ ) and the optical density at $600 \mathrm{~nm}$ was recorded. The cells were permeabilized using $0.01 \%$ Toluene and $0.01 \%$ SDS. For the reaction, $50 \mu \mathrm{L}$ of the permeabilized cells were diluted into $450 \mu \mathrm{L}$ of LB broth. The diluted cells were then added to $500 \mu \mathrm{L}$ of PM2 $\left(70 \mathrm{mM} \mathrm{Na}_{2} \mathrm{HPO}_{4}\right.$ $\mathrm{H} 2 \mathrm{O}, 30 \mathrm{mM} \mathrm{NaHPO} 4-\mathrm{H} 2 \mathrm{O}, 1 \mathrm{mM} \mathrm{MgSO}_{4}$, and 0.2 $\mathrm{mM} \mathrm{MnSO}_{4}$ ) buffer containing $100 \mathrm{mM} \beta$-mercaptoethanol. The reaction was initiated by adding $250 \mu \mathrm{L}$ of $12 \mathrm{mg} / \mathrm{mL}$ ortho-nitrophenyl- $\beta$-galactoside and allowed to continue for 15 seconds at $28^{\circ} \mathrm{C}$. The reaction was stopped by the addition of $500 \mu \mathrm{L}$ of $1.0 \mathrm{M}$ $\mathrm{Na}_{2} \mathrm{CO}_{3}$. The absorbance was measured at $420 \mathrm{~nm}$ and the $\beta$-galactosidase activity was expressed as units of $\beta$ galactosidase activity per milligram of bacteria. Empty pT18 and pT25 vectors were transformed into $E$. coli DHP1 cells as a negative control and pT18-CopN and pT25-CdsN were used as a positive control (38). The cutoff for a positive interaction (677 units activity/mg bacteria) was determined as the mean plus two standard deviations of the negative control values obtained from 20 assays.

\section{Acknowledgements}

We would like to thank Dr. Patrik Bavoil for scientific discussion involving the flagellar proteins. CBS is a recipient of a Father Sean O'Sullivan Research Center Studentship. This research was funded in part by a Canadian Institute of Health Research grant to JBM.

\section{Authors' contributions}

CS performed most of the experimental work. DB aided in the bacterial-2hybrid studies. JG cloned and expressed Cpn0322. RT explored potential oligomerization of Flil. JM coordinated the work and edited the manuscript. All authors read and approved of the final manuscript.

Received: 27 July 2009

Accepted: 22 January 2010 Published: 22 January 2010

\section{References}

1. Hahn D, Azenabor A, Beatty W, Byrne G: Chlamydia pneumoniae as a respiratory pathogen. Front Biosci 2002, 7:e66-e76.

2. Grayston J: Background and current knowledge of Chlamydia pneumoniae and atherosclerosis. J Infect Dis 2000, 181:S402-S410.

3. Ardeniz O, Gulbahar O, Mete N, Cicek C, Basoglu OK, Sin A, et al: Chlamydia pneumoniae arthritis in a patient with common variable immunodeficiency. Ann Allergy Asthma Immunol 2005, 94:504-508.

4. Balin B, Little C, Hammond C, Appelt D, Whittum-Hudson J, Gerard H, et al: Chlamydophila pneumoniae and the etiology of late-onset Alzheimer's disease. J Alzheimers Dis 2008, 13:371-380.

5. Clifton D, Fields K, Grieshaber S, Dooley C, Fischer E, Mead D, Carabeo R, Hackstadt T: A chlamydial type III translocated protein is tyrosinephosphorylated at the site of entry and associated with recruitment of actin. Proc Natl Acad Sci USA 2004, 101:10166-10171.

6. Lane B, Mutchler C, Khodor S, Grieshaber S, Carabeo R: Chlamydial entry involves TARP binding of guanine nucleotide exchange factors. PLOS Pathog 2008, 4:1-11.

7. Coombes B, Mahony J: Identification of MEK- and phosphoinositide-3kinase-dependant signaling as essential events during Chlamydia pneumoniae invasion of HEp2 cells. Cell Microbiol 2002, 4:447-460.

8. Moulder J: Interaction of chlamydiae and host cells in vitro. Microbiol Rev 1991, 55:143-190.

9. Hatch T: Utilization of L-cell nucleoside triphosphates by Chlamydia psittaci for ribonucleic acid synthesis. J Bacterio/ 1975, 122:393-400. 
10. Moore E, Fischer E, Mead D, Hackstadt T: The Chlamydial inclusion preferentially intercepts basolaterally directed sphingomyelin-containing exocytic vacuoles. Traffic 2008, 9:2130-2140.

11. Wylie J, Hatch G, McClarty G: Host cell phospholipids are trafficked to and then modified by Chlamydia trachomatis. J Bacteriol 1997, 179:7233-7242.

12. Heuer D, Lipinski A, Machuy N, Karlas A, Wehrens A, Siedler F, Brinkmann V, Meyer T: Chlamydia causes fragmentation of the Golgi compartment to ensure reproduction. Nature 2009, 457:731-735.

13. Hoare A, Timms P, Bavoil P, Wilson D: Spatial constraints within the chlamydial host cell inclusion predict interrupted development and persistence. BMC Microbiol 2008, 8:5.

14. Scidmore M, Hackstadt T: Mammalian 14-3-3beta associates with the Chlamydia trachomatis inclusion membrane via its interaction with IncG. Mol Microbiol 2001, 39:1638-1650.

15. Hybiske K, Stephens R: Mechanisms of host cell exit by the intracellular bacterium Chlamydia. Proc Natl Acad Sci USA 2007, 104:11430-11435.

16. Stone C, Johnson D, Bulir D, Mahony J: Characterization of the putative type III secretion ATPase CdsN (Cpn0707) of Chlamydophila pneumoniae. J Bacterio/ 2008, 190:6580-6588.

17. Blaylock B, Riordan K, Missiakas D, Schneewind O: Characterization of the Yersinia enterocolitica type III secretion ATPase $\mathrm{YscN}$ and its regulator YscL. J. Bacteriol 2006, 188:3525-3534.

18. Fields K, Hackstadt T: Evidence for the secretion of Chlamydia trachomatis CopN by a type III secretion mechanism. Mol. Microbiol 2000, 38:1048-1060.

19. Riordan $\mathrm{K}$, Schneewind $\mathrm{O}$ : YscU cleavage and the assembly of Yersinia type III secretion machine complexes. Mol Microbiol 2008, 68:1485-1501.

20. Johnson D, Stone C, Mahony J: Interactions between CdsD, CdsQ, and CdsL, three putative Chlamydophila pneumoniae type III secretion proteins. J Bacteriol 2008, 190:2972-2980.

21. Aizawa S: Bacterial flagella and type III secretion systems. FEMS Microbiol Lett 2001, 202:157-164

22. Kalman S, Michell W, Marathe R, Lammel C, Fan J, Hyman R, Olinger L, Grimwood J, Davis R, Stephens R: Comparative genomes of Chlamydia pneumoniae and C. trachomatis. Nat Genet 1999, 21:385-389.

23. Peters J, Wilson J, Myers G, Timms P, Bavoil P: Type III secretion a la Chlamydia. Trends Microbiol 2007, 15:241-251.

24. Ghelardi E, Celandroni F, Salvetti S, Beecher D, Gominet M, Lereclus D, Wong A, Senesi S: Requirement of flhA for swarming differentiation, flagellin export, and secretion of virulence-associated proteins in Bacillus thuringiensis. J Bacteriol 2002, 184:6424-6433.

25. McMurry J, Arnam J, Kihara M, Macnab R: Analysis of the cytoplasmic domains of Salmonella FlhA and interactions with components of the flagellar export machinery. J Bacteriol 2004, 186:7586-7592.

26. Bigot A, Pagniez H, Botton E, Frehel C, Dubail I, Jacquet C, Charbit A, Raynaud C: Role of FliF and Flil of Listeria monocytogenes in flagellar assembly and pathogenicity. Infect Immune 2005, 73:5530-5539.

27. Akeda Y, Galan J: Chaperone release and unfolding of substrates in type III secretion. Nature 2005, 437:911-915.

28. Paul K, Erhardt M, Hirano T, Blair D, Hughes K: Energy source of flagellar type III secretion. Nature 2008, 451:489-492.

29. Kubori T, Shimamoto N, Yamaguchi A, Namba K, Aizawa S: Morphological pathway of flagellar assembly in Salmonella typhimurium. J Mol Biol 1992, 226:433-446.

30. Soscia C, Hachani A, Bernadac A, Filloux A, Bleves S: Cross talk between type III secretion and flagellar assembly systems in Pseudomonas aeruoginosa. J Bacteriol 2007, 189:3124-3132.

31. Berg H: The rotary motor of bacterial flagella. Annu Rev Biochem 2003 72:19-54.

32. Marykwas D, Schmidt S, Berg H: Interacting components of the Flagellar Motor of Escherichia coli revealed by the two-hybrid system in Yeast. $J$ Mol Bio 1996, 256:564-576.

33. Kihara M, Minamino T, Yamaguchi S, Macnab R: Intergenic suppression between the flagellar MS ring protein FliF of Salmonella and FlhA a membrane component of its export apparatus. J Bacteriol 2001, 183:1655-1662

34. McMurry J, Arnam J, Kihara M, Macnab R: Analysis of the cytoplasmic domains of Salmonella FlhA and interactions with components of the flagellar export machinery. J Bacteriol 2004, 186:7586-7592.
35. Minamino T, Macnab R: Interactions among components of the Salmonella flagellar export apparatus and its substrates. Molecular Microbiology 2000, 35:1052-1064.

36. Minamino T, Macnab M: FliH a soluble component of the type III flagellar export apparatus of Salmonella, forms a complex with Flil and inhibits ATPase activity. Mol Microbiol 2000, 37:1494-1503.

37. Okabe M, Minamino T, Imada K, Namba K, Kihara M: Role of the N-terminal domain of Flil ATPase in bacterial flagellar protein export. FEBS lett 2009, 583:743-748.

38. Pallen M, Bailey C, Beatson S: Evolutionary links between FliH/YscL-like proteins from bacterial type III secretion systems and second-stalk components of the $\mathrm{F}_{0} \mathrm{~F}_{1}$ and vacuolar ATPases. Protein Sci 2006, 15:935-940.

39. Fraser G, Gonzalez-Pedrajo B, Tame J, Macnab R: Interactions of FliJ with the Salmonella type III flagellar export apparatus. J Bacteriol 2003, 185:5546-5554.

40. Minamino T, Namba K: Distinct roles of the Flil ATPase and proton motive force in bacterial flagellar protein export. Nature 2008, 451:485-488

41. Andrade A, Pardo J, Espinosa N, Perez-Hernandez G, Gonzalez-Pedrajo B: Enzymatic characterization of the enteropathogenic Escherichia coli type III Secretion ATPase EscN. Arch Biochem Biophys 2007, 468:121-127.

42. Fan F, Macnab R: Enzymatic characterization of Flil. J Biol Chem 1996, 271:31981-31988.

43. Imada K, Minamino T, Tahara A, Namba K: Structural similarity between the flagellar type III ATPase Flil and F1-ATPase subunits. Proc Natl Acad Sci USA 2007, 104:485-490.

44. Minamino T, Chu R, Yamaguchi S, Macnab R: Role of FliJ in flagellar protein export in Salmonella. J. Bacteriol 2000, 182:4207-4215.

45. Karimova G, Dautin N, Ladant D: Interaction network among Escherichia coli membrane proteins involved in cell division as revealed by bacterial two-hybrid analysis. J Bacteriol 2005, 187:2233-2243.

doi:10.1186/1471-2180-10-18

Cite this article as: Stone et al.: Interactions between flagellar and type III secretion proteins in Chlamydia pneumoniae. BMC Microbiology 2010 10:18.

\section{Submit your next manuscript to BioMed Central and take full advantage of:}

- Convenient online submission

- Thorough peer review

- No space constraints or color figure charges

- Immediate publication on acceptance

- Inclusion in PubMed, CAS, Scopus and Google Scholar

- Research which is freely available for redistribution

Submit your manuscript at www.biomedcentral.com/submit
Biomed Central 